University of Nebraska - Lincoln

DigitalCommons@University of Nebraska - Lincoln

\title{
A Cellulose Fiber-Based Diet for Screwworm (Diptera: Calliphoridae) Larvae
}

M. F. Chaudhury

USDA-ARS, mchaudhury2@aol.com

Steven R. Skoda

University of Nebraska-Lincoln, sskoda1@unl.edu

Follow this and additional works at: https://digitalcommons.unl.edu/usdaarsfacpub

Part of the Agricultural Science Commons

Chaudhury, M. F. and Skoda, Steven R., "A Cellulose Fiber-Based Diet for Screwworm (Diptera: Calliphoridae) Larvae" (2007). Publications from USDA-ARS / UNL Faculty. 787.

https://digitalcommons.unl.edu/usdaarsfacpub/787

This Article is brought to you for free and open access by the U.S. Department of Agriculture: Agricultural Research Service, Lincoln, Nebraska at DigitalCommons@University of Nebraska - Lincoln. It has been accepted for inclusion in Publications from USDA-ARS / UNL Faculty by an authorized administrator of DigitalCommons@University of Nebraska - Lincoln. 


\title{
A Cellulose Fiber-Based Diet for Screwworm (Diptera: Calliphoridae) Larvae
}

\author{
M. F. CHAUDHURY ${ }^{1}$ AND S. R. SKODA \\ Screwworm Research Unit, USDA-ARS, Apartado Postal 544, Tuxtla Gutierrez, Chiapas, Mexico
}

J. Econ. Entomol. 100(1): 241-245 (2007)

\begin{abstract}
A highly absorbent cellulose fiber from recycled paper was tested and compared with a polyacrylate gelling agent, Aquatain, normally used for bulking and solidifying larval rearing medium of screwworm, Cochliomyia hominivorax (Coquerel) (Diptera: Calliphoridae). The absorbent fiber, when mixed with water and dietary ingredients, produced a diet medium of homogeneous texture that supported larval growth and development comparable with the standard gelled diet. Larval and pupal weights from two concentrations of cellulose fiber-based diet were significantly higher than those obtained using gelled diet. The number of pupae per tray, percentage of adult emergence, oviposition, percentage of egg hatch, and adult longevity obtained from the insects reared in the cellulose fiber-based diet were comparable or slightly better than the biological parameters recorded from flies reared in the gelled diet. Moreover, results indicate that a lesser amount of the cellulose fiber-based diet than the normal amount of gelled diet per tray would support normal larval growth. Physical properties and texture of the new diet seem to allow the larvae to move and feed more freely than they do on the semisolid gelled diet, resulting in less wasted diet. The cellulose fiber is biodegradable and inexpensive, whereas the polyacrylate gel polymer is not biodegradable and is relatively expensive. Replacing gel with cellulose fiber in the screwworm larval diet for mass rearing should result in substantial cost savings in material and labor as well as eliminating concern of environmental pollution due to diet waste disposal.
\end{abstract}

KEY WORDS cellulose fiber, larval diet, rearing, screwworm, spray-dried blood

Mass rearing of New World screwworm, Cochliomyia hominivorax (Coquerel), by the Mexico-U.S. Commission for the Eradication of Screwworm is one of the largest insect rearing programs in the world. C. hominivorax has been eradicated from the United States, Mexico and the Central American countries by using the sterile insect technique. The goal of the eradication program at present is to eliminate the insect from some of the Caribbean Islands to prevent possible reinfestation of the eradicated areas. The mass production facility, located in Chiapa de Corzo, Chiapas, Mexico, currently produces $\approx 100$ million flies per week to supply sterile insects to the eradication program in Jamaica as well as to Panama to maintain a sterile fly barrier zone between Panama and Colombia to prevent movement of fertile flies from Colombia. Nearly $20,000 \mathrm{~kg}$ of dry food at a cost of about US $\$ 30,000$ per week is required for this purpose. Most of the cost and the labor needed for $C$. hominivorax

This article reports the results only. The use of trade, firm or corporation names in this publication is for information and convenience of the reader. Such use does not constitute an official endorsement or approval by USDA or ARS of any product or service to the exclusion of others that may be suitable.

${ }^{1}$ Corresponding author, e-mail: mchaudhury2@aol.com. mass production is dedicated to rearing larvae. More than 15, 000 liters of larval diet is prepared daily.

Until recently, the larval diet used for mass rearing was the gelled diet that was slightly modified from that of Taylor et al. (1991) and consisted of $6 \%$ spray dried whole bovine blood, $4 \%$ inedible egg product, $4 \%$ milk substitute (a milk protein + soy protein product), and $1.8 \%$ gelling agent, Aquatain, mixed with $0.1 \%$ formalin (to prevent microbial growth) and $84.1 \%$ water. The gelling agent Aquatain, a hydrophilic sodium polyacrilonitrile polymer, was used to solidify the liquid rearing medium previously used for mass rearing screwworm larvae. The gelling agent does not have any nutritional value. Several gelling agents from various sources have been tested (Harris et al. 1984, 1985; Taylor and Mangan 1987; Taylor 1988; Taylor et al. 1991; Chaudhury and Alvarez 1999). The consistency of diet mixed with most of these gelling agents remains relatively constant over a wide range of humidity; the diet remains semisolid, and is acceptable to the larvae for a longer period before becoming contaminated by toxic waste products (Taylor 1988; Chaudhury and Alvarez 1999; M.F.C, unpublished data). However, the gelling agent is the most expensive of all ingredients used for the larval diet, and it is a nonbiodegradable polymer causing problems with waste disposal. 
Chaudhury et al. (2002) tested absorbent recycled paper products as substitutes for gelling agent. Products such as terra-mulch, processed from recycled newsprint for mulching purposes were successfully used as bulking and solidifying agent in place of gel to produce a diet of homogeneous texture that supported larval growth and development comparable with the standard diet prepared with the gelling agent (Chaudhury et al. 2002; M.F.C., unpublished data). These products were inexpensive and biodegradable but not suitable for mass rearing due to irregular supply and lack of guaranteed freedom of contaminants which may harm or kill developing larvae.

Recently, we tested another product derived from recycled newsprint and other waste paper products that was less expensive than the other paper products we tested earlier and relatively easier to mix with the dietary ingredients. This product, a superfine cellulose fiber, trade named CF-100, is commercially manufactured in large quantities and normally used as a paint thickener, hydro-seeding mulch, and landfill cover and for erosion control. Furthermore, the product is guaranteed to be free of harmful chemicals and is environmentally safe.

In previous experiments with paper products from recycled newsprints, we noted that the texture of the diet containing recycled paper products was different from that of the gelled diet (Chaudhury et al. 2002). The diet with the paper products was relatively porous and consequently the developing larvae had greater ease of mobility allowing feeding to the deepest layer of the diet. The physical texture of the gelled diet indicated that the dietary ingredients remained adsorbed tightly to the gel, causing some difficulty in larval feeding, whereas the dietary ingredients in the paper-based diet remained suspended in a thick slurry and were easily available to the larvae (Chaudhury et al. 2002). These observations suggested that the waste of gel-based diet, discarded after larval maturation, contained considerable amounts of unused dietary ingredients. Therefore, a paper-based diet may require less dietary ingredients per tray but still allow adequate larval growth and development or more larvae to be reared per tray. Furthermore, better porosity of the paper-based diet (unlike gelled diet) that allows larvae to feed through the deepest layers of the diet may allow reducing the feeding frequency, thereby reducing the cost of labor.

This article reports the results of tests using a new cellulose fiber-based diet that is very effective for larval growth and development and has potential to replace the gel as the bulking and solidifying agent. Additional benefits of a reduced amount of diet per tray and reduction of the frequency of feeding would be economically beneficial for mass rearing of screwworms.

\section{Materials and Methods}

The cellulose fiber, CF-100, was obtained as a sample from the Central Fiber Corporation (Wellsville, KS) and the sodium polyacrylate gel Aquatain was purchased from the Pioneer Medical Inc. (Lakeland, FL). Three dietary ingredients, i.e., spray-dried whole bovine blood and spray-dried poultry egg were purchased from the California Spray Dry Co. (Stockton, CA), and the dry milk substitute was from the Calva Products Co. Inc. (Acampo, CA). Tests were conducted on the Panama-95 strain of screwworm developed by the Agricultural Research Service from Panama screwworm flies collected in 1995 .

The diet with 5 or $6 \%$ cellulose fiber was prepared by mixing 50 (or 60 ) g of CF-100 with 810 (or 800 ) ml of warm tap water $\left(39 \pm 1^{\circ} \mathrm{C}\right.$ ) and $1 \mathrm{ml}$ of formalin (as an antimicrobial agent), and then adding $60 \mathrm{~g}$ of spraydried blood, $40 \mathrm{~g}$ of spray-dried egg, and $40 \mathrm{~g}$ of milk substitute. The ingredients were thoroughly mixed with an electric mixer at medium speed for $5 \mathrm{~min}$. The mixture yielded 1 liter of ready-to-use diet. The gel diet was prepared by mixing the same amounts of dietary ingredients (blood, egg, and milk) with $18 \mathrm{~g}$ of the gel Aquatain, adding $842 \mathrm{ml}$ of warm water mixed with $1 \mathrm{ml}$ of formalin to the dry ingredient, and then similarly mixing for 5 min to yield 1 liter of diet. The temperature and $\mathrm{pH}$ of each of the mixed diets were recorded to ascertain that the variations in their physical properties were negligible among the batches of the diets prepared. Insect rearing and the measurements of the parameters were carried out according to Chaudhury et al. (2002) with some modifications as detailed under each of the experimental procedures below.

Comparison of Diets. These tests were conducted to compare two cellulose fiber-based diets ( 5 and $6 \%$ concentrations of cellulose fiber) with the standard gelled diet, in terms of larval and pupal weight, number of pupae per tray, percentage of adult emergence, amount of eggs laid, percentage of egg hatch, and adult longevity in days. Diets were prepared fresh each day for all tests. Essentially, the tests were conducted according to the procedures reported by Chaudhury et al. $(1998,2002)$.

Each larval rearing tray $(25.5$ by 18.5 by $9.5 \mathrm{~cm}$ in depth) received a total of 1.5 liters of diet in three feedings $(300,600$, and $600 \mathrm{ml}$ on day 0,2 , and 3 of the experiment, respectively). Each tray received $100 \mathrm{mg}$ of eggs $(\approx 2,000$ eggs $)$. Eggs were placed on a piece of moist paper towel ( 3 by $3 \mathrm{~cm}$ ) on top of the initial 300 $\mathrm{ml}$ of diet in the plastic tray. The rearing trays were placed in the larval rearing room $\left(38 \pm 1^{\circ} \mathrm{C}\right.$ and $75 \pm$ $5 \% \mathrm{RH}$ ). The next day, the eggs hatched, and the newly emerged larvae started to feed on the diet. The two additional feedings were poured on top of the old media. Mature (third instar) larvae started crawling out of the media on day 5 after hatch and dropped on to sawdust $(2 \mathrm{~cm}$ in depth) provided in a pan ( 28 by 24 by $13 \mathrm{~cm}$ in depth) held under each tray, where pupation occurred. A sample of 100 larvae was randomly taken from each tray and weighed. Five days after pupation, pupae from each tray were sifted from the sawdust and weighed. At the same time, a sample of 100 pupae was taken randomly from each tray and weighed; from the two weights, the total number of pupae in each tray was determined. One hundred 
pupae from each tray were held in small cages, allowed to emerge, and percentage of emergence was recorded. Longevity was determined by holding 100 newly emerged flies in cages with honey and water and recording their mortality until $50 \%$ of the flies survived. To determine fecundity, 500 mated females from each tray were held in a cage with a diet of honey mixed with spray-dried egg and water (Chaudhury et al. 2000). When the females were $7 \mathrm{~d}$ old, a petri dish with $5 \mathrm{~g}$ of horse meat were introduced into the cage to induce oviposition. After allowing $2 \mathrm{~h}$ for oviposition, the petri dish was removed from the cage, and the egg batches were collected and weighed. To determine fertility, two samples of $100 \mathrm{mg}$ of eggs from each test were placed in petri dishes lined with moist filter paper and incubated at $38 \pm 1^{\circ} \mathrm{C}$ for $\approx 20 \mathrm{~h}$. Unhatched eggs and egg shells from each petri dish were collected, counted under a microscope $(10 \times$ magnification), and a percentage of hatch was determined. Tests were replicated five times with four trays per replicate.

Amounts of Diet. These tests were conducted to compare larval and pupal weights and pupal yield from varying amounts of cellulose fiber-based diet ( $5 \%$ cellulose fiber) with those parameters obtained from insects reared on a gelled diet of standard amount and feeding frequency. One gram of eggs $(\approx 20,000$ eggs $)$ was placed on 5- by 5-cm moist paper towel on top of prepared diet in a standard 15-liter galvanized tray (63 by 43 by $6 \mathrm{~cm}$ ) placed on the racks in the rearing room $\left(38 \pm 1^{\circ} \mathrm{C}\right.$ and $\left.75 \pm 5 \% \mathrm{RH}\right)$. The amount of the first feeding on day 0 for each tray (for both control and test trays) was 3 liters for incubation and initial feeding of the newly hatched larvae. A second feeding of 7 liters per tray was added to each tray on day 2. On day 3 , treatment $\mathrm{A}$ trays received no diet, but the treatments $\mathrm{B}, \mathrm{C}$, and $\mathrm{D}$ received 1,2 , and 3 liters of diet per tray, respectively. The control received 5 liters on day 3. The total amount of diet per tray for A was 10 liters; B, 11 liters; C, 12 liters; and D, 13 liters; control trays received the standard amount of 15 liters of the gelled diet. Mature larvae started crawling out of the media on day 5 after hatch and dropped on to sawdust provided under each tray where pupation occurred. Larval and pupal weights and the number of total pupae were determined using the procedures described under Comparison of Diets. Tests were run in four replicates with four trays per replicate.

Frequency of Feeding. These tests were conducted to compare larval and pupal weights and pupal yield obtained using 15 liters of cellulose fiber based diet (5\% cellulose fiber) offered at varying frequencies during the larval developmental period with those obtained using the standard gelled diet. One gram of eggs was placed on a 5 - by 5 -cm moist paper towel on top of the prepared diet that was placed in each 15liter galvanized tray. The trays were placed on the racks in the rearing room $\left(38 \pm 1^{\circ} \mathrm{C}\right.$ and $\left.75 \pm 5 \% \mathrm{RH}\right)$. Three treatments were compared with the control: one treatment $(\mathrm{X})$ received only one feeding of 15 liters at day 0 ; the second $(\mathrm{Y})$ was run with two feedings: the first feeding of 7 liters at day 0 and a
Table 1. Life history parameters (mean \pm SD) of screwworm reared on diets prepared with cellulose fiber-based diet (CF) compared with those from gelled diet

\begin{tabular}{lccc}
\hline \hline \multicolumn{1}{c}{ Parameter $(F, P)$} & $5 \% \mathrm{CF}$ & $6 \% \mathrm{CF}$ & Gelled diet \\
\hline Larval wt, mg $\left(28.9^{*}, 0.00\right)$ & $71.7 \pm 2.4 \mathrm{a}$ & $69.5 \pm 2.6 \mathrm{a}$ & $59.6 \pm 4.5 \mathrm{~b}$ \\
Pupal wt, mg $\left(17.1^{*}, 0.00\right)$ & $54.3 \pm 2.7 \mathrm{a}$ & $52.2 \pm 1.8 \mathrm{a}$ & $43.6 \pm 2.9 \mathrm{~b}$ \\
No. pupae/tray $(1.55,0.25)$ & $1618 \pm 255$ & $1708 \pm 314$ & $1650 \pm 228$ \\
\% adult emergence & $95.5 \pm 2.8$ & $94.1 \pm 1.7$ & $95.5 \pm 1.7$ \\
$\quad(2.51,0.08)$ & & & \\
Eggs laid, g (0.32, 0.92) & $4.3 \pm 0.8$ & $4.1 \pm 1.1$ & $4.2 \pm 1.5$ \\
\% egg hatch (0.28, 0.88) & $92.2 \pm 4.2$ & $90.4 \pm 3.3$ & $89.6 \pm 3.1$ \\
Longevity, d $(0.18,0.94)$ & $13.7 \pm 3.6$ & $14.8 \pm 4.2$ & $13.1 \pm 0.9$ \\
\hline
\end{tabular}

* Mean $\pm \mathrm{SD}$, means for each parameter followed by different letters are significantly different by Tukey's range test after a significant $F$ value $(\mathrm{df}=2 ; P=0.05)$.

second feeding of 8 liters at day 3 . The third $(\mathbf{Z})$ was run with three feedings: the first feeding of 4 liters at day 0 , the second of 7 liters at day 2 , and the third feeding of 4 liters at day 3 . The gelled diet control received three feedings as described for the third treatment $(\mathbf{Z})$. The trays for the tests with reduced frequency of the diet were sprayed daily with $\approx 10 \mathrm{ml}$ of water per tray starting on day 2 of the experiment to prevent the diet from drying. Larval and pupal weights and the number of total pupae were determined as described under Comparison of Diets. Tests were run in four replicates with four trays per replicate.

Statistics. Data were statistically evaluated with analysis of variance (ANOVA) by using complete randomized block design followed by Tukey's multiple range tests to separate means after a significant $F$ value (Sokal and Rohlf 1981, NCSS 2000).

\section{Results}

Comparison of Diets. Seven life parameters-larval weight, pupal weight, number of pupae, percentage of emergence, fecundity, percentage of egg hatch, and adult longevity - were compared. Means and SDs of these life stages resulting from larvae reared on two diets based on cellulose fiber (CF-100) and a control diet, the standard gel (Aquatain)-based diet are presented in Table 1. Larval and pupal weights of the insects reared on both the cellulose fiber diets were significantly higher that those obtained from insects reared on gelled diet. These two parameters did not vary significantly within the two cellulose fiber diets. The number of pupae per tray, percentage of emergence, oviposition, egg hatch, and adult longevity were similar in all treatments showing no significant differences in any of the parameters.

Amounts of Diet. Larval weight, pupal weight, and number of pupae per tray obtained from four different treatments of reduced quantities of cellulose fiberbased diet were compared with those obtained from the standard 15-liter amount of gelled diet (Table 2). Larval and pupal weights obtained from insects reared in 10 liters of diet were significantly lower than those reared in 15-liter control diet; there were no significant differences in these parameters from insects 
Table 2. Comparison of life history parameters (mean \pm SD) of screwworm reared on varying amt of cellulose fiber-based diet and gel-based diet of standard amount (control)

\begin{tabular}{lccrcc}
\hline \hline \multicolumn{1}{c}{ Parameters $(F, P)$} & $\mathrm{A}^{a}$ & $\mathrm{~B}$ & $\mathrm{C}$ & $\mathrm{D}$ & Control \\
\hline Larval wt, mg (14.9*, 0.00) & $54.1 \pm 2.5 \mathrm{a}$ & $55.5 \pm 2.5 \mathrm{ab}$ & $57.4 \pm 2.3 \mathrm{~b}$ & $60.6 \pm 2.4 \mathrm{c}$ & $57.6 \pm 2.9 \mathrm{~b}$ \\
Pupal wt, mg (17.7*,0.00) & $38.9 \pm 1.9 \mathrm{a}$ & $40.2 \pm 1.9 \mathrm{ab}$ & $41.6 \pm 2.1 \mathrm{~b}$ & $46.4 \pm 1.6 \mathrm{c}$ & $41.2 \pm 2.2 \mathrm{~b}$ \\
No. pupae/tray $(1.6,0.18)$ & $15,870 \pm 1,180$ & $15,776 \pm 1,108$ & $16,316 \pm 1,288$ & $15,509 \pm 1,210$ & $16,793 \pm 1,835$ \\
\hline
\end{tabular}

${ }^{a}$ A, 10 liters-day 0 (3 liters), day 2 (7 liters); B, 11 liters-day 0 (3 liters), day 2 ( 7 liters), day 3 (1 liter); C, 12 liters-day 0 (3 liters), day 2 ( 7 liters), day 3 (2 liters); D, 13 liters-day 0 (3 liters), day 2 (7 liters), day 3 (3 liters); and control, 15 liters-day 0 (4 liters), day 2 (7 liters), day 3 (4 liters).

* Mean \pm SD, means for each parameter followed by different letters are significantly different by Tukey's range test after a significant. $F$ value $(\mathrm{df}=4, P=0.05)$.

reared in 11 and 12 liters of diet compared with those obtained from the control. However, the larvae and pupae obtained from the treatment with 13 liters of diet were significantly larger than those produced by the control diet. Numbers of pupae per tray from all four test diets were not significantly different from each other or from the control diet.

Frequency of Feeding. Larval weight, pupal weight, and number of pupae per tray obtained from three different treatments of varying the feeding frequency of the cellulose fiber-based diet were compared with those obtained from the standard gelled diet fed three times during the complete larval development (Table 3 ). The numbers of pupae obtained from all treatments were not significantly different. Larval and pupal weights obtained from the treatment having only one offer of the total amount of diet (15 liters) were significantly lower that those obtained from the control diet fed at normal frequency. The weights recorded from the treatment having the total amount of diet divided into two feedings and offered at $0 \mathrm{~h}(7$ liters) and at $72 \mathrm{~h}$ (8 liters) of development were not significantly different than the control diet. However, the weights recorded from the treatment having the total amount of the cellulose fiber-based diet portioned three ways and fed at three different times exactly as the control were significantly different (higher) compared with those parameters from the control diet.

\section{Discussion}

Results of this investigation show that the commercially available cellulose fiber, CF-100, has the potential for use in the screwworm larval diet and can effectively replace the gelling agent Aquatain. The diets with the cellulose fiber CF-100 produced larvae and pupae larger than those produced by the gelled diet, indicating superior growth and development in the cellulose fiber-based diets. Pupal yield per tray, adult emergence rate, longevity, egg production, and hatching resulting from the insects reared in both gelled diet and the new cellulose fiber-based diet in these studies were similar in all respects to the parent colony maintained in our laboratory for 16 generations on gelled diet during the time of experiments as well as to those routinely obtained in the mass production system (M.F.C., unpublished data).

In experiments dealing with varying amounts of the diet, 10 liters of cellulose fiber-based diet produced significantly smaller larvae, indicating insufficient nutrients for normal larval weight gain; however, 11 and 12 liters of diet produced larvae that were as large as the larvae produced by the 15 liters of gelled diet, indicating that these amounts of cellulose fiber-based diet provided as much nutrients as the 15 liters of gelled diet. This was probably because the cellulose fiber based diet was relatively porous, allowing larvae to have better accessibility and mobility for feeding, thereby resulting in more effective nutrient ingestion and use. Moreover, the dietary ingredients in cellulose fiber were evenly dispersed and remained suspended in slurry as reported previously with the diets prepared using various paper products as the bulking agents (Chaudhury et al. 2002). The gelled diet, however, was firmer in consistency where the dietary ingredients adhered tightly to the gel. Consequently, the larvae probably experienced difficulty in feeding adequately and thereby were unable to access sufficient nutrient materials for normal development. Interestingly, the test with 13 liters of cellulose fiberbased diet produced significantly larger larvae and pupae than those produced by 15 liters of gelled diet. This result clearly indicates that acceptable quality

Table 3. Comparison of life history parameters (mean \pm SD) of screwworm reared on cellulose fiber-based diet offered in varying frequency and gel-based diet offered in standard frequency

\begin{tabular}{lccrr}
\hline \hline \multicolumn{1}{c}{ Parameter $(F, P)$} & $\mathrm{X}^{a}$ & $\mathrm{Y}$ & $\mathrm{Z}$ & Control \\
\hline Larval wt, mg (13.1*, 0.00) & $52.8 \pm 5.4 \mathrm{a}$ & $63.4 \pm 2.4 \mathrm{~b}$ & $66.9 \pm 3.6 \mathrm{c}$ & $60.4 \pm 3.1 \mathrm{~b}$ \\
Pupal wt, mg (25.1*,0.00) & $37.6 \pm 3.2 \mathrm{a}$ & $45.5 \pm 2.2 \mathrm{~b}$ & $47.8 \pm 2.2 \mathrm{c}$ & $44.1 \pm 2.3 \mathrm{~b}$ \\
No. pupae/tray $(0.8,0.53)$ & $18,414 \pm 1,090$ & $18,390 \pm 2,064$ & $17,884 \pm 1,530$ & $17,620 \pm 870$ \\
\hline
\end{tabular}

${ }^{a} \mathrm{X}, 15$ liters in single feeding; Y, two feedings—-day 0 (7 liters), day 3 (8 liters); Z, three feedings-day 0 (4 liters), day 2 (7 liters), day 3 (4 liters); and control, three feedings of gelled diet as $\mathbf{Z}$.

* Mean \pm SD, means for each parameter followed by different letters are significantly different by Tukey's range test after a significant. $F$ value $(\mathrm{df}=3 ; P=0.05)$. 
insects ( $>40 \mathrm{mg}$ of pupa) can be produced using 13 , 12 , or even 11 liters of cellulose fiber-based diet as opposed to 15 liters of gelled diet. Because of the physical properties of the gelled diet, a considerable amount of nutrients that are not available to the larvae is wasted. This reduction in amount of diet required would be a significant saving in cost of mass rearing.

Results of experiments dealing with frequency of feeding indicate that a single offer of the total diet ration cannot support normal larval development. Although the quantity of pupae obtained was comparable with that obtained from the control (where diet was offered three times at various intervals of larval development) the quality of insects was not acceptable (below 40-mg pupae). Although the full complement of the diet was available to the larvae, albeit in a single offer, the quality of the diet probably deteriorated for reasons such as the accumulation of toxic waste contaminating the entire feeding area and resulting in less feeding. In addition, the loss of moisture might have created a relatively dry and unfavorable feeding environment. These problems are prevented from occurring by multiple offering of the diet in smaller portions. Results of the treatment where the feeding frequency was reduced to two times show similar development as in the control (three feedings) indicating that the cellulose fiber-based diet at the reduced frequency would support normal larval growth. It should be noted that the surface of the diet on trays in the tests with reduced feeding frequency exhibited considerable dryness due to loss of moisture, a condition normally not observed in the three-feeding regimen; to prevent this drying out, additional moisture was provided by spraying water on the surface of the diet in these tests with negligible cost in labor.

Cellulose fiber CF-100 was easier to handle and mix with dietary ingredients than the paper products used in previous experiments (Chaudhury et al. 2002). The fiber length of the product was sufficiently short $(\approx 1$ $\mathrm{mm}$ ) to prepare a diet as a homogeneous slurry, a desirable physical feature for optimum larval feeding. Cellulose fiber does not have any nutritional value for screwworm, and the larvae do not seem to ingest the fiber along with the nutrients.

Cellulose fiber, CF-100 is cheaper (US\$0.50/ kg) than other paper products previously used and gel (US $\$ 6.00 / \mathrm{kg}$ ). An estimate with just the material cost indicates that replacing gel with cellulose fiber for mass rearing 150 million pupae per week would result in a savings of more than US $\$ 100,000$ annually. The cellulose fiber-based diet has recently been adopted for mass rearing to replace the gelled diet where it has produced much larger pupae and adults than the gelled diet. Most likely, these robust males would compete more effectively in the field as sterile males in the eradication program, because earlier studies on screwworm mating competence indicate that smaller males are less competitive (Pitti 2001). Additional savings may result from reduction of labor for rearing with a strategy of feeding at reduced frequency. Because of its biodegradable nature, cellulose fiberbased diet waste may be disposed of in a landfill or composted without further processing as is required for gel-based diet waste. Improvements in rearing such as these should result in a more effective, sustainable and environmentally friendly eradication and exclusion program against screwworms.

\section{Acknowledgments}

We thank John P. Spencer (USDA-APHIS) and Dennis R. Berkebile (USDA-ARS) for suggestions and critical reading of the manuscript. Technical assistance of Alfredo Alvarez, Celia Jimenez, Delfina Cruz, and Lupita Hernandez of USDA-ARS, Screwworm Research Laboratory, Tuxtla Gutierrez, Mexico, is gratefully acknowledged.

\section{References Cited}

Chaudhury, M. F., and L. A. Alvarez. 1999. A new starchgrafted gelling agent for screwworm (Diptera: Calliphoridae) larval diet. J. Econ. Entomol. 92: 1138-1141.

Chaudhury, M. F., L. A. Alvarez, and J. B. Welch. 1998. An alternative source of blood protein for screwworm (Diptera: Calliphoridae) larval diet. J. Econ. Entomol. 91: 1397-1400.

Chaudhury, M. F., L. A. Alvarez, and L. L. Velazquez. 2000. A meatless diet for adult screwworm (Diptera: Calliphoridae). J. Econ. Entomol. 93: 1398-1401.

Chaudhury, M. F., L. A. Alvarez, and L. L. Velazquez. 2002. Recycled paper products as substitutes for gelling agent in screwworm (Diptera: Calliphoridae) larval diet. J. Econ. Entomol. 95: 1337-1341.

Harris, R. L., R. D. Peterson, M. E. Vasquez-G., and O. H. Graham. 1984. Gelled media for the production screwworm larvae. Southwest. Entomol. 9: 257-262.

Harris, R. L., E. F. Gersabeck, C. Corso, and O. H. Graham. 1985. Screwworm larval production on gelled media. Southwest. Entomol. 10: 253-256.

[NCSS] Number Cruncher Statistical System. 2000. NCSS statistical system for Windows, user's manual, version 6 . NCSS, Kaysville, UT.

Pitti, A. 2001. The effect of the adult screwworm male size on mating competence. M.S. thesis, University of Nebraska, Lincoln, NE.

Sokal, R. R., and F. J. Rohlf. 1981. Biometry. Freeman, New York.

Taylor, D. B. 1988. Comparison of two gelling agents for screwworm (Diptera: Calliphoridae) larval diet. J. Econ. Entomol. 81: 1414-1419.

Taylor, D. B., and R. L. Mangan. 1987. Comparison of gelled and meat diets for rearing screwworm, Cochliomyia hominivorax (Diptera: Calliphoridae) larvae. J. Econ. Entomol. 80: 427-432.

Taylor, D. B., J. C. Bruce, and R. Garcia. 1991. Gelled diet for screwworm (Diptera: Calliphoridae) mass production. J. Econ. Entomol. 84: 927-935.

Received 21 July 2006; accepted 26 October 2006. 